\title{
Human Metapneumovirus: A Newly Described Respiratory Tract Pathogen
}

\author{
William A. Alto, MD
}

Human metapneumovirus is an emerging human respiratory pathogen first discovered in 2001. It clinically resembles respiratory syncytial virus, can cause both upper and lower tract disease, and has been associated with serious illness in the young, among the immunosuppressed, and in the chronically ill. Cough and congestion are frequently reported, and respiratory failure may occur. Initial infection occurs during early childhood, and repeated infections throughout life impart only transient immunity. Diagnosis is by reverse transcription-polymerase chain reaction or rising serologic titers. No commercial laboratory tests or treatments are available. Primary care physicians should maintain vigilance for outbreaks of newly discovered and emerging respiratory illnesses. (J Am Board Fam Pract 2004;17: 466-9.)

Acute respiratory tract infections (ARIs) are important causes of illness and mortality worldwide. In the United States, ARIs are the sixth leading cause of death and account for more than half a million hospital admissions and 8 to 10 million outpatient visits per year. ${ }^{1,2}$ The bacterial or viral agent responsible for an ARI is often uncertain. In $40 \%$ to $60 \%$ of community-acquired pneumonias, the pathogenic agent remains undetermined. ${ }^{3}$ A similar situation exists with ARIs that are presumed to be viral. ${ }^{4-9}$ Two or more causative agents probably occur more frequently than are currently documented.

Recent progress in epidemiologic surveillance and molecular biology has allowed the rapid recognition and identification of several newly emerging respiratory pathogens. In the last decade, the bird flu (avian influenza A, H5 N1), severe acute respiratory syndrome (SARS) coronavirus, and human metapneumovirus (HMPV) have been discovered, their viruses isolated, and clinical data from infected patients compiled and published. Recent research indicates that HMPV is the cause of an important proportion of acute

Submitted, revised, 5 August 2004.

From the Maine-Dartmouth Family Practice Residency, Fairfield. Address correspondence to William A. Alto, MD, Maine-Dartmouth Family Practice Residency, 4 Sheridan Drive, Fairfield, ME 04937 (e-mail: waalto@dartmouth. edu). upper and lower respiratory tract infections in all age groups. ${ }^{10-13}$

\section{The Virus}

In 2001, a new respiratory tract viral pathogen, human metapneumovirus, was first reported from the Netherlands. ${ }^{11}$ The virus was identified in 28 stored nasopharyngeal aspirates collected over a 20 -year period. Its discovery may have been delayed because the virus replicates poorly on routinely used continuous cell lines. Using random arbitrarily primed-polymerase chain reaction, the virus was found to be in the Paramyxoviridae family, the first human pathogen of the genus Metapneumovirus. Both respiratory syncytial (RSV) and parainfluenza viruses are paramyxoviruses and are well known to clinicians. An indirect immunofluorescent antibody test was developed that allows serologic diagnosis. With the virus identified and a serologic test available, researchers have begun exploring the epidemiology and clinical presentations of the disease. It occurs in seasonal outbreaks that seem to coincide with RSV season. ${ }^{10,13}$ The incubation period was 5 to 6 days based on a single documented hospital-acquired infection. ${ }^{5}$ An attempt to identify the virus in 400 healthy children under 2 years of age was unsuccessful, ${ }^{11}$ although asymptomatic and carrier states have been reported in children and adults. ${ }^{10,12}$ Because most descriptions of clinical signs and symptoms are based on studies of children ill enough to require hospital- 


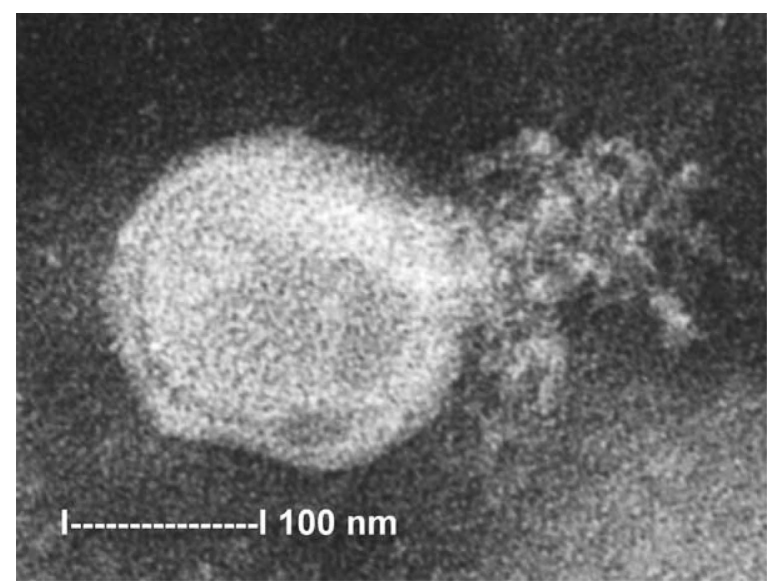

Figure 1. Electron micrograph of human metapneumovirus collected from the supernatant of rhesus monkey kidney (LLC-MK2) cell culture. A virion-releasing nucleocapsid is shown. [Reprinted from Chan PK, Tam JS, Lam G-W, et al. Human metapneumovirus detection in patients with severe acute respiratory syndrome. Emerg Infect Dis 2003;9: 1058-63].

ization, a true picture of the pathogenicity of HMPV is still emerging (Figure 1).

\section{Epidemiology}

The HMPV has been reported worldwide. One hundred percent of 72 stored serum samples from children and adults collected in 1958 were positive for HMPV, indicating that the virus has been circulating in human populations for years. ${ }^{11}$ Seroprevalence increased from $25 \%$ in children between 6 months and 1 year old to $100 \%$ in those over 5 years of age. ${ }^{11}$ There are at least 2 different genetic lineages, and viral genome heterogeneity may also allow for incomplete immunity and repeated infections. ${ }^{10,14,15}$ Human metapneumovirus infection accounts for approximately $2 \%$ to $12 \%$ of pediatric lower respiratory illnesses and a lesser percentage in adults. ${ }^{4-10,12,13,15-18}$ Antibody titers in children increased with age, which suggests boosting of antibody response. ${ }^{11}$

\section{Clinical Features in Children}

In infants and children, lower respiratory tract illness caused by HMPV is similar to other viralassociated bronchiolitis and cannot clinically be distinguished from the RSV, influenza, and parainfluenza viruses. Cough was reported in more than
$90 \%$ of children; more than $75 \%$ had rhinorrhea, and more than $50 \%$ had fever. ${ }^{4-10,13,16}$ An exacerbation of existing asthma or wheezing was present in about one half. Hypoxia and abnormal chest radiograph findings were common in hospitalized patients; perihilar infiltrates, peribronchial thickening, and air trapping were reported. ${ }^{13}$ Found less frequently were otitis media, diarrhea, rash, conjunctivitis, and febrile seizures. ${ }^{5,7}$ Most infants and children received a discharge diagnosis of bronchiolitis, croup, pneumonia, bronchitis, or asthma exacerbation (in decreasing order of frequency). ${ }^{7,10,15,16}$ Co-infection with other respiratory viruses occurs, and simultaneous infection with HMPV and RSV has been postulated to cause severe disease, often requiring intensive care admission and ventilatory support. ${ }^{17}$ The disease is believed to more serious in infants and in those with chronic illnesses, ${ }^{18}$ and one death in an immunocompromised child has been reported. ${ }^{19}$ Primary infection with the virus is believed to cause the most severe symptoms.

Few articles have reported laboratory data. One report of 32 hospitalized children under the age of 18 months noted that $29 \%$ had lymphopenia and $6 \%$ had elevated transaminases. ${ }^{5}$ In another series of 10 hospitalized children, normal white blood cell counts and elevated C-reactive protein levels were reported. ${ }^{8}$

\section{Adult Disease}

Several community studies in adults have helped to define the role of HMPV as the cause of ambulatory ARIs. ${ }^{12,20}$ Two longitudinal studies, one conducted in British general practices over a single winter ${ }^{20}$ and the other in adults in Rochester, New York, over 2 winter seasons, ${ }^{12}$ reported HMPV infection rates of $2.2 \%$ and $1.5 \% / 7.0 \%$, respectively. In the majority of healthy young and elderly adults, HMPV was predominately a mild disease characterized by cough, hoarseness, congestion, and rhinorrhea. ${ }^{12}$ Sore throat, hoarseness, sputum production, and constitutional symptoms were present in more than half of patients. Fever was unusual. Immunocompromised and chronically ill patients often require hospitalization. ${ }^{12,21}$ No laboratory results of adults with HMPV have been reported. Treatment has been supportive.

The HMPV is not the pathogenic agent responsible for Severe Acute Respiratory Syndrome 
(SARS). But the 2 illnesses overlap in their signs and symptoms. Of interest is a report that $40 \%$ of 48 patients admitted to a Hong Kong hospital with suspected SARS were infected with HMPV alone, and $12 \%$ had HMPV plus SARS coronavirus. Only $10 \%$ had the SARS virus alone. ${ }^{22}$ A similar finding has been reported from Toronto. ${ }^{23}$ A 40-year-old man who met the World Health Organization's criteria for probable SARS was discovered at postmortem examination to have died of HMPV pneumonitis. ${ }^{24}$

\section{Conclusions}

The newly discovered human metapneumovirus is an important cause of community-acquired acute respiratory infections in infants, children, and adults. Both the upper and lower respiratory tracts may be involved, and serious illness may occur in the very young and in those who are chronically ill or immunosuppressed. Further research should answer the many questions about HMPV.

The increased interest in respiratory pathogens, coupled with heightened surveillance and improved laboratory methods, will lead to the discovery of new pathogenic agents causing pneumonia-like illness. Up-to-date knowledge and heightened awareness by primary care physicians are essential in the recognition of new diseases or patterns of disease because we are the first line of defense in Public Health efforts to limit the epidemic spread of emerging pathogens.

I appreciate the technical assistance from Colleen Flewelling and Donal Gordon.

\section{References}

1. Bartlett JG, Dowell SF, Mandell LA, File Jr TM, Musher DM, Fine MJ. Practice guidelines for the management of community-acquired pneumonia in adults. Infectious Diseases Society of America. Clin Infect Dis 2000;31:347-82.

2. Schappert SM. Ambulatory care visits to physician offices, hospital outpatient departments, and emergency departments: United States, 1997. Vital Health Stat 13 1999;(143):i-iv, 1-39.

3. Bartlett JG, Breiman RF, Mandell LA, File TM Jr. Community-acquired pneumonia in adults: guidelines for management. The Infectious Disease Society of America. Clin Infect Dis 1998;26:811-38.

4. Boivin G, De Serres G, Cote S, et al. Human metapneumovirus infections in hospitalized children. Emerg Infect Dis 2003;9:634-40.
5. Peiris JS, Tang WH, Chan KH, et al. Children with respiratory disease associated with metapneumovirus in Hong Kong. Emerg Infect Dis 2003;9:628-33.

6. Vicente D, Cilla G, Montes M, Perez-Trallero E. Human metapneumovirus and community-acquired respiratory illness in children [letter]. Emerg Infect Dis 2003;9:602-3.

7. Freymouth F, Vabret A, Legrand L, et al. Presence of the new human metapneumovirus in French children with bronchiolitis [letter]. Pediatr Infect Dis J 2003;22:92-4.

8. Jartti T, van den Hoogen B, Garofalo R, et al. Metapneumovirus and acute wheezing in children [letter]. Lancet 2002;360:1393-4.

9. Nissen MD, Mackay IM, Withers SJ, Siebert DJ, Sloots TP. Evidence of human metapneumovirus in Australian children [letter]. Med J Australia 2002; 176:188-9.

10. Williams JV, Harris PA, Tollefson SJ, et al. Human metapneumovirus and lower respiratory tract disease in otherwise healthy infants and children. N Eng J Med 2004;350:443-50.

11. van den Hoogen BG, deJong JC, Groen J, et al. A newly discovered human pneumovirus isolated from young children with respiratory tract disease. Nat Med 2001;7:719-24.

12. Falsey AR, Erdman D, Anderson LJ, Walsh EE. Human metapneumovirus infections in young and elderly adults. J Infect Dis 2003;187:785-90.

13. Mullins JA, Erdman DD, Weinberg GA, et al. Human metapneumovirus infection among children hospitalized with acute respiratory illness. Emerg Infect Dis 2004;10:700-5.

14. Peret TC, Boivin G, Li Y, et al. Characterization of human metapneumoviruses isolated from patients in North America. J Infect Dis 2002;185:1660-3.

15. Viazov S, Ratjen F, Scheidhauer R, Fiedler M, Roggendorf $M$. High prevalence of human metapneumovirus infection in young children and genetic heterogeneity of the viral isolates. J Clin Microbiol 2003;41:3043-5.

16. Esper F, Boucher D, Weibel C, Mortinello RA, Kahn JS. Human metapneumovirus infection in the United States: clinical manifestations associated with a newly emerging respiratory infection in children. Pediatrics 2003;111:1407-10.

17. Greensill J, McNamara PS, Dove W, Flanagan B, Smyth RL, Hart CA. Human metapneumovirus in severe respiratory syncytial virus bronchiolitis. Emerg Infect Dis 2003;9:372-5.

18. Maggi F, Pifferi M, Vatteroni M, et al. Human metapneumovirus associated with respiratory tract infections in a 3-year study of nasal swabs from infants in Italy. J Clin Microbiol 2003;41:2987-91.

19. Pelletier G, Dery P, Abed Y, Boivin G. Respiratory tract reinfections by the new human Metapneumovirus in an immunocompromised child. Emerg Infect Dis 2002;8:976-8. 
20. Stockton J, Stephenson I, Fleming D, Zambon M. Human metapneumovirus as a cause of communityacquired respiratory illness. Emerg Infect Dis 2002; 8:897-901.

21. Boivin G, Abed Y, Pelletier G, et al. Virological features and clinical manifestations associated with human metapneumovirus: a new paramyxovirus responsible for acute respiratory-tract infections in all age groups. J Infect Dis 2002;186:1330-4.

22. Chan PK, Tam JS, Lam G-W, et al. Human metapneumovirus detection in patients with severe acute respiratory syndrome. Emerg Infect Dis 2003;9: $1058-63$.

23. Poutanen SM, Low DE, Henry B, et al; National Microbiology Laboratory, Canada; Canadian Severe Acute Respiratory Syndrome Study Team. Identification of severe acute respiratory syndrome in Canada. N Engl J Med 2003 15;348:1995-2005.

24. Chan PK, To K-F, Wu A, et al. Human metapneumovirus-associated atypical pneumonia and SARS. Emerg Infect Dis 2004;10:497-500. 